Gazi University
Journal of Science
http://dergipark.gov.tr/gujs

\title{
Production of Plastic Injection Molds with Conformal Cooling Channels by Laminated Brazing Method
}

\author{
Mustafa GOKTAS ${ }^{1, *}$ (D) , Abdulmecit GULDAS ${ }^{2}$ (D) \\ ${ }^{1}$ Gazi University, Technical Sciences Vocational School, 06374, Ankara, Turkey \\ ${ }^{2}$ Gazi University, Department of Manufacturing Engineering, 06560, Ankara, Turkey
}

\author{
Highlights \\ - Design of plastic injection mold with conformal cooling channels. \\ - Manufacturing of conformal cooling channels by Vacuum Brazing method. \\ - Improving plastic part quality and cycle time in plastic injection molding.
}

Article Info
Received: $19 / 09 / 2019$
Accepted: $25 / 02 / 2020$
Keywords
Conformal cooling channels
Plastic injection molding
Cooling system
Vacuum brazing
Warpage of plastic parts

\section{INTRODUCTION}

One of the cheapest and most common methods used to produce plastic parts is plastic injection molding. The molten plastic that fills to the cavity in the mold needs to be cooled in a controlled manner. The cooling process is carried out by means of a cooling system on the mold. Cooling plastic injection molds is a very critical phase as it directly affects production speed and product quality [1,2]. The cooling time corresponds to approximately $80 \%$ of the total cycle time [3]. Improvement in the efficiency of the cooling system improves product quality and production speed.

Plastic injection molds are traditionally cooled by passing cooling water through the straight cooling channels formed by drilling the mold plates $[4,5]$. Straight cooling channels cannot provide the proper temperature distribution needed in inclined surfaces, regions and corners with different wall thicknesses [6]. In regions where cooling is not effective, it takes longer to fully solidify of molten plastic. The distance between the straight cooling channel and complex shaped surfaces varies with the slope of the surface [7]. Therefore, a more suitable cooling system is required for plastic parts with complex geometry. The location of the cooling channel significantly affects the cooling process and the solidification rate of the molten plastic [8]. There are two main critical points in the design of cooling systems: shortening cycle time and uniform temperature distribution [9]. 
In a group of studies, a systematic method was presented for the design of the conformal cooling channels that were not affected by the designer's experience [10-12]. Conformal cooling channels were used for the cooling operation which was more compatible with the geometry of the mold cavity [13-16].

Thanks to metal laser sintering technologies, it is possible to manufacture plastic injection molds with conformal cooling channels. With the help of this production method, restrictions on the design of cooling channels are removed [17]. However, since the material produced by metal laser sintering method has a porous structure, it cannot provide the expected mechanical properties for plastic injection molds. Another drawback caused by the porous structure is the low thermal conductivity. Also, the cost of this production method is still quite high. Material improvement studies on metal laser sintering method are ongoing [18, 19].

In another study proposed in the literature, an alternative method was presented for the production of plastic injection molds with conformal cooling channels. For this purpose, three-dimensional cooling channels were tried to be obtained by milling the back side of the mold plates [20-23].

In another method, although not very precise, a plastic injection mold with a conformal cooling channel was manufactured with welded metal deposition [24].

More industrial production methods are being explored for the manufacturing of molds with conformal cooling channels. Studies in this field show that more applicable production methods are needed for the production of the mold plates with conformal cooling channels. Multi-part production of plastic injection molds with conformal cooling channels comes to the fore [25]. Vacuum brazing is a method that provides a durable joining of mold parts to mechanical loads and sealing [26-29].

In this study, a practical and cost-effective method for the production of conformal cooling channels is presented. Unlike the studies in the literature, mold cores were produced in pieces, and then the pieces were combined with the vacuum brazing method. Plastic injection molds with conformal cooling channels could thus be produced from steel material with high thermal conductivity and mechanical strength. An experimental study was carried out to achieve this. Mold cores with conformal cooling channels were made of steel plates. The gaps that would form the conformal cooling channels were engraved on the plates by milling. The plates were combined with brazing, and mold blocks were formed. Mold cores and cavities were manufactured by milling the obtained blocks again. Plastic parts were produced by using mold with linear cooling channel and mold with conformal cooling channel separately. The produced plastic parts and cooling times were examined, and both types of molds were compared.

\section{MATERIAL AND METHOD}

\subsection{Plastic Part and Cooling Channel Design}

For the experimental study, a plastic part was designed with geometry that straight cooling channels couldn't follow conformably. There are inclined surfaces on the plastic part as is seen in Figure 1. ABS (Acrylonitrile Butadiene Styrene) was chosen as plastic part material. Dimensions of the plastic part are $149 \times 94 \times 41 \mathrm{~mm}$ and the wall thickness is $3.5 \mathrm{~mm}$.

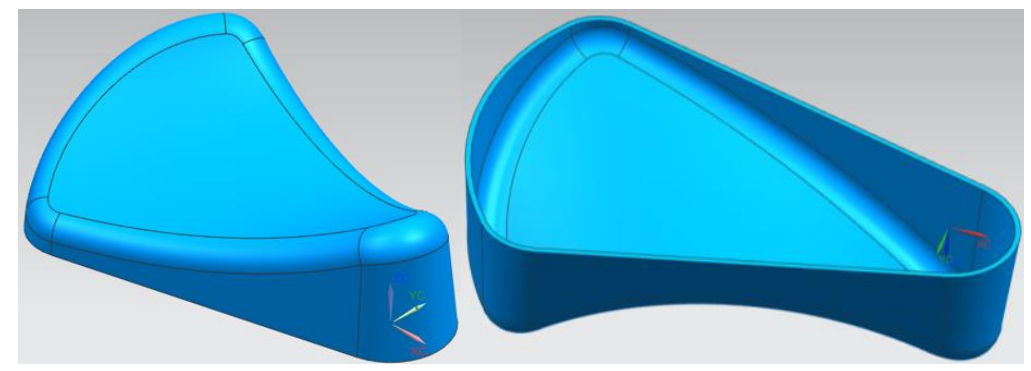

Figure 1. Plastic part geometry used in the stud 
Conformal cooling channels were designed by using a design method developed in the previous study [11]. In order for the cooling channels to be located at a fixed distance from the mold cavity, both the inner and outer surfaces of the plastic part were offsetted, and the offset surfaces were created (Figure 2). The center of the conformal cooling channel was located on these surfaces (Figure 3).

Figures should be separated from the text by one single line (before and after the text). Figure and the caption can be either left or center justified. Figure caption should be in italic font. Excel files (i.e. graphs) should not be embedded directly into the text. Instead, they should be converted to image files or copy/pasted to the text as images.

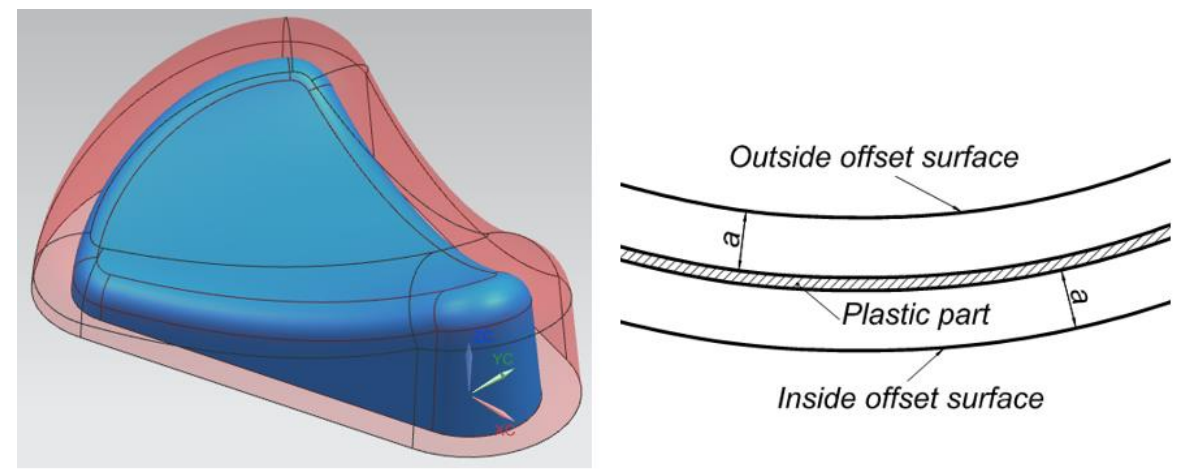

Figure 2. The offset surfaces [11]

As seen in Figure 4, conformal cooling channels have been designed for both halves of the mold (bottom and top plates). The offset distance of the surface determines the distance between the axis of the cooling channel and the mold cavity. The channel dimensions were determined depending on the wall thickness of the plastic part [30]. The channel diameter is $10 \mathrm{~mm}$, the distance of the channels to each other is $25 \mathrm{~mm}$, and the distance between the channel and the mold cavity is $17 \mathrm{~mm}$.

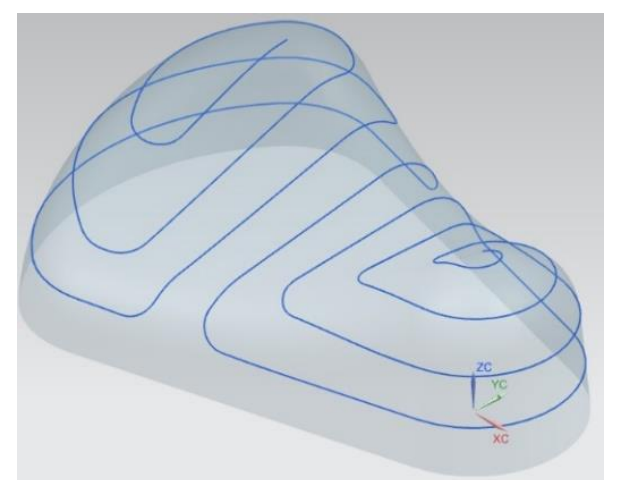

Figure 3. The channel axis is located on the offset surface [11]

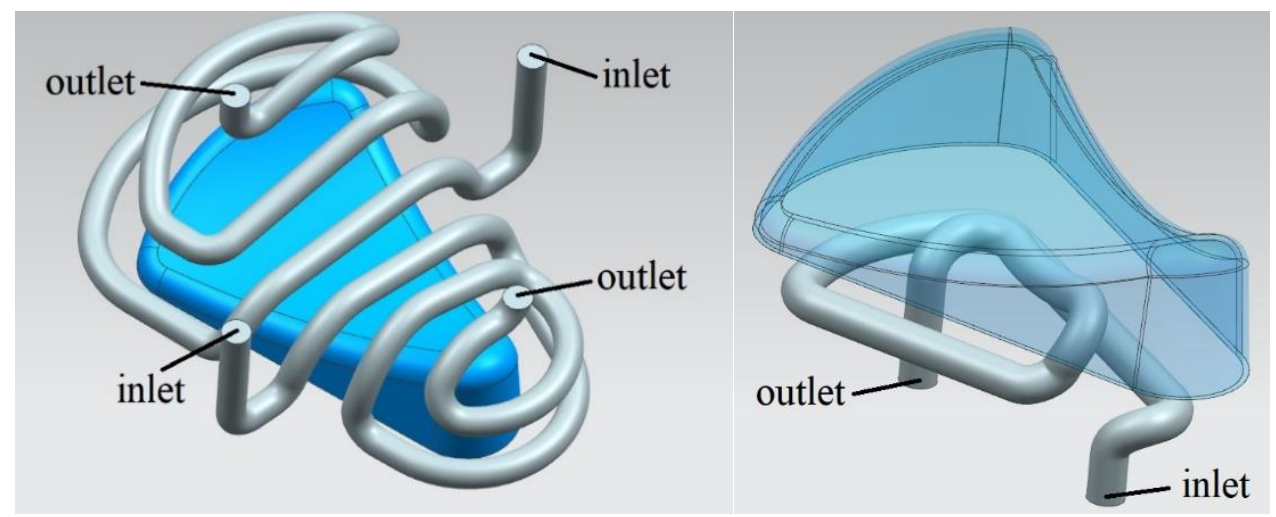

Figure 4. Conformal cooling channels at both sides 
Straight cooling channels were also designed to compare the difference between the conformal cooling channels and the straight cooling channel (Figure 5). As is seen in Figure 5, the straight channels consist of four drilled holes. The straight cooling channels on the same mold half were connected in series outside the mold.

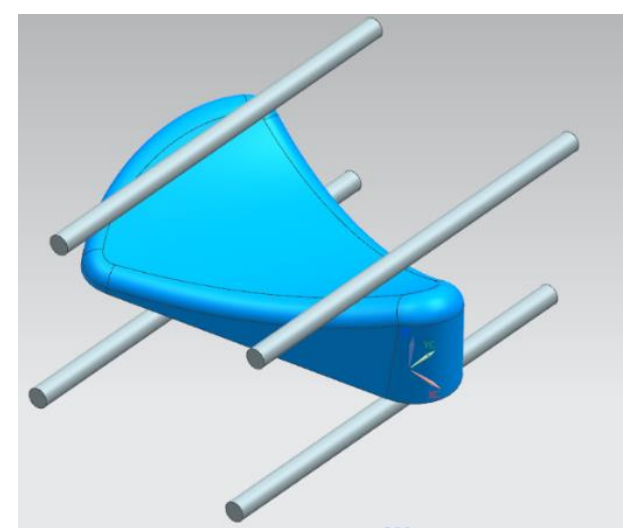

Figure 5. The straight cooling channels

\subsection{Manufacturing of Plastic Injection Mold}

A laminated production method was used for the production of the mold sets with conformal cooling channels. The solid model of the plastic injection mold was divided into layers (Figure 6). The layer thicknesses were determined to be suitable for milling the gaps formed by the cooling channels.

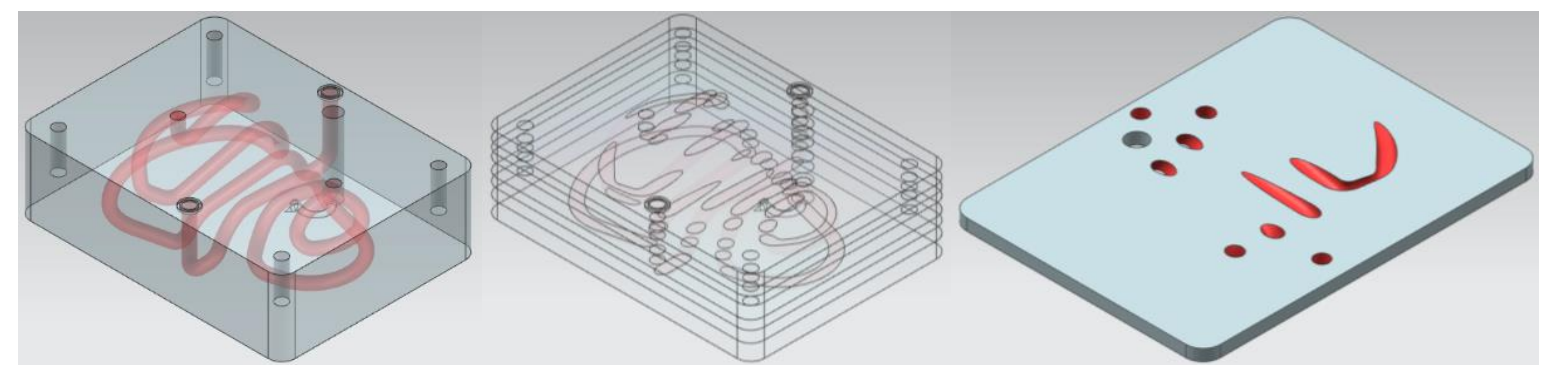

a) b)

Figure 6. Obtaining splits plates. a) Dividing the mold cores into layers, $b$ ) The obtained plate

The surfaces of the steel plates were precisely machined by grinding to manufacture the divided parts. The material properties of the steel plates are shown in Table 1.

Table 1. Chemical properties of the mold material, \%

\begin{tabular}{|c|c|c|c|c|c|}
\hline Standard (ISO) & $C$ & $M n$ & $S i$ & $P$ & $S$ \\
\hline 1.0037 & $0.17-0.2$ & 1.4 & 0.3 & 0.045 & 0.009 \\
\hline
\end{tabular}

The plates manufactured by CNC milling were combined with the vacuum brazing method. The parts to be joined before soldering were mechanically and chemically cleaned. The joining surfaces were ground for the mechanical cleaning. Unlike the diffusion source, the surfaces were left grinded to allow the molten soldering material to penetrate the surface scratches with capillary action. No additional polishing was applied.

The surfaces to be joined were cleaned from the oxide layer and dirt with ethyl alcohol. Copper-based soldering material was used to the joining surfaces. The properties of the soldering material are shown in Table 2 . 
Table 2. Properties of soldering material

\begin{tabular}{|c|c|c|c|c|c|}
\hline EN 1044 & $A W S$ A5.8 & DIN 8513 & $\mathrm{Cu} \%$ & Sn \% & Melt Temperature ${ }^{\circ} \mathrm{C}$ \\
\hline CU101 & Bcu-1a & $L-C u$ & 100 & - & 1083 \\
\hline
\end{tabular}

Then the parts to be joined with the centering pins were aligned to each other. Soldering was carried out in an atmosphere-controlled vacuum furnace, in a nitrogen / hydrogen $(90 \% / 10 \%)$ gas atmosphere, at $1100^{\circ} \mathrm{C}$ for 5 minutes holding time. While brazing, a load was placed on the plates to prevent the mold plates separating from each other and drift apart.

After the joining, the blocks with conformal cooling channels were milled on the CNC machine, and the mold cores and cavities were formed (Figure 7). Polishing process was not applied to the mold surfaces.

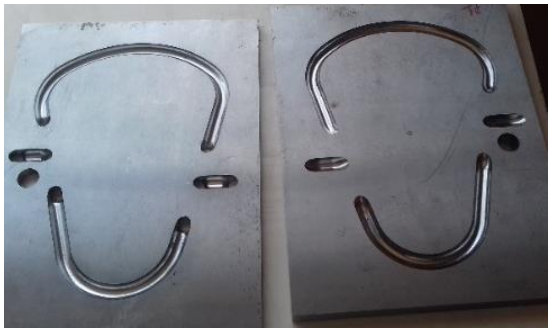

a)

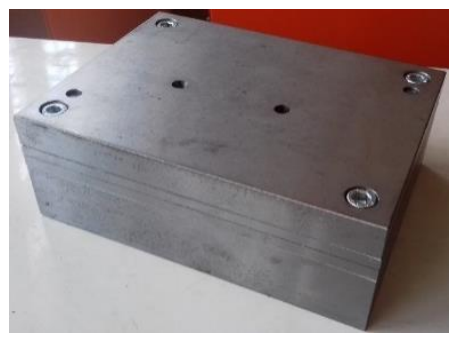

b)

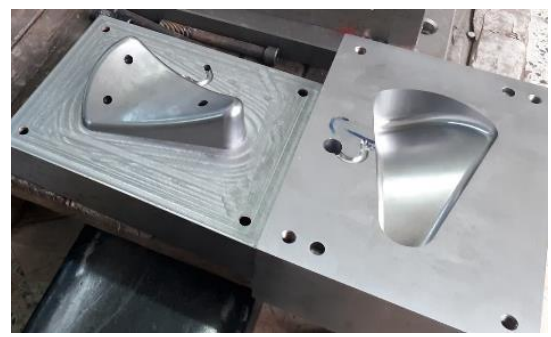

c)

Figure 7. Mold cores with conformal cooling channels. a) Joined plates, b) Brazed plates, c) precision machined mold cores

\subsection{Measuring of Warpage on The Plastic Parts}

In plastic injection molding process, while plastic material cools, shrinkage occurs. As the shrinkage occurs, the temperature distribution on the plastic material also affects the shrinkage phenomenon. As a result of the absence of a uniform temperature distribution, the plastic part warps. With the use of conformal cooling channel, it was aimed to cool the plastic part with a more uniform temperature distribution. The effect of the cooling process performed with the conformal cooling channel on the amount of warpage on the plastic parts was tried to be determined. The amount of warpage on the produced plastic parts were examined and compared. The warpage depths on the planar surface on the plastic part were measured with a dial indicator (Figure 8).

The processing parameters used in the producing trials are shown in Table 3. Mold conditioning unit was used to keep the mold temperature constant. The coolant temperature was kept constant at $60^{\circ} \mathrm{C}$.

Mold temperature was continuously controlled with k-type thermocouple and data logger. The surface temperature of the ejected part from the mold was measured with an infrared thermometer (Standard Infrared Thermometer ST-8858). The surface temperature measurement of the plastic part was carried out as soon as the ejector pins dropped the plastic part after the mold was opened.

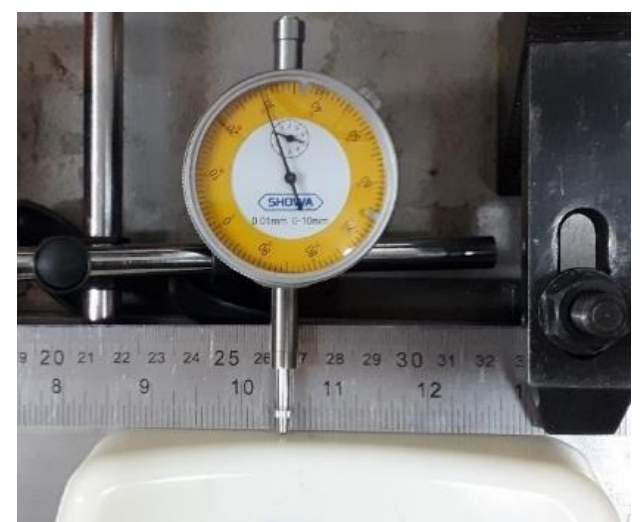

Figure 8. Comparison of the amount of warpage depths on plastic parts 
Table 3. Injection parameters

\begin{tabular}{|l|c|}
\hline Melt temperature, ${ }^{\circ} \mathrm{C}$ & 240 \\
\hline Mold temperature, ${ }^{\circ} \mathrm{C}$ & 60 \\
\hline Ejection temperature, ${ }^{\circ} \mathrm{C}$ & 90 \\
\hline Injection pressure, bar & 45 \\
\hline Packing pressure, bar & 30 \\
\hline
\end{tabular}

\section{EXPERIMENTAL RESULTS AND DISCUSSIONS}

The plastic injection mold with conformal cooling channels was designed and divided into layers. The parts that formed the mold cores were produced by joining with the vacuum brazing method. In addition, the mold cores with straight cooling channels were produced for the comparison. ABS was used as a plastic material in producing trials. The properties of the plastic material are shown in Table 4. Producing trials were carried out by connecting the prepared plastic injection molds to the plastic injection machine.

Table 4. Properties of the plastic material

\begin{tabular}{|c|c|c|c|c|c|c|}
\hline Material & $\begin{array}{c}\text { Density } \\
\mathrm{kg} / \mathrm{cm}^{3}\end{array}$ & $\begin{array}{c}\text { Injection } \\
\text { Temperature } \\
{ }^{\circ} \mathrm{C}\end{array}$ & $\begin{array}{c}\text { Mold } \\
\text { Temperature } \\
{ }^{\circ} \mathrm{C}\end{array}$ & $\begin{array}{c}\text { Heat } \\
\text { Deflection } \\
\text { Temperature } \\
{ }^{\circ} \mathrm{C}\end{array}$ & $\begin{array}{c}\text { Drying } \\
\text { Temperature } \\
{ }^{\circ} \mathrm{C}\end{array}$ & $\begin{array}{c}\text { Drying } \\
\text { Time } \\
\mathrm{h}\end{array}$ \\
\hline $\begin{array}{c}\text { LGCHEM } \\
\text { ABS HI121 }\end{array}$ & 1.04 & $210-240$ & $40-70$ & 91 & 80 & $2-4$ \\
\hline
\end{tabular}

The cooling time was adjusted so that the surface temperature of the ejected plastic part would be $90^{\circ} \mathrm{C}$. Preparation producing were carried out to balance the mold temperature. 30 parts were produced in both types of cooling channels (Figure 9).

Effects of the straight and conformal cooling channels on cooling time were examined (Table 5). Cooling time was observed as $32 \mathrm{~s}$ when using straight cooling channel, and cooling time was observed as $25 \mathrm{~s}$ when using conformal cooling channel. Figure 10 shows the time reach of the ejection temperature graphically.

The total cycle time decreased from $44 \mathrm{~s}$ to $37 \mathrm{~s}$ with the use of conformal channels. The effect of the conformal cooling channels in the cooling process can be clearly seen in Figure 9. The using of conformal cooling channels increased the production speed.

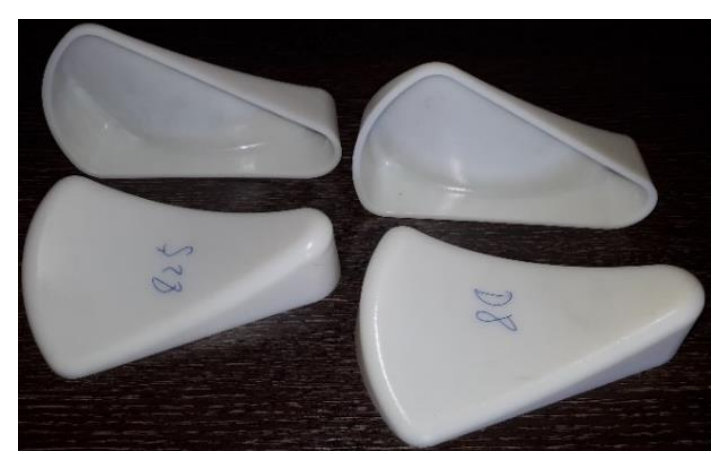

Figure 9. Plastic parts produced with conformal (left) and straight (right) cooling channel

Although the production costs of the molds with straight cooling channels was lower than the conformal cooling channels, increasing the production speed provided an advantage in reducing the total costs. With this regard, compared to additive manufacturing methods, this method is very advantageous in terms of mold production costs. 


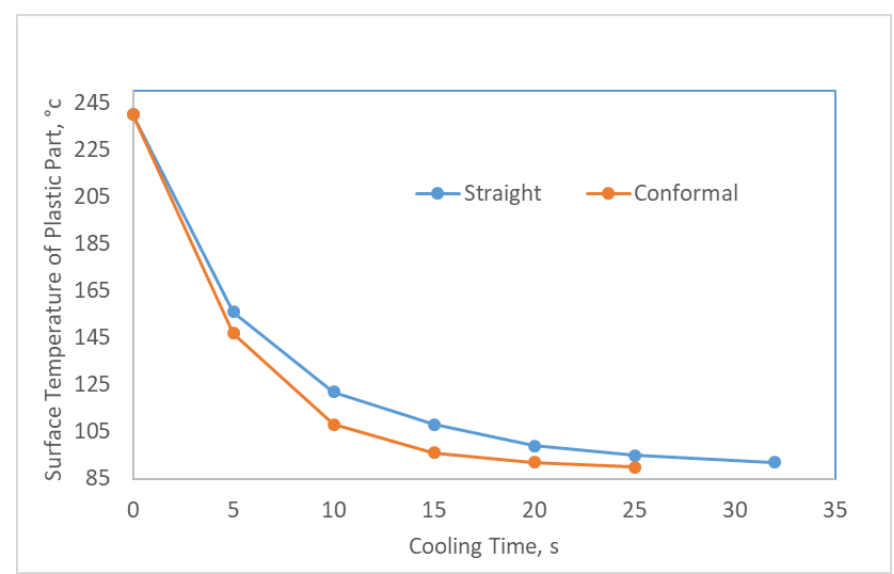

Figure 10. Plastic part surface temperatures by time

In the plastic injection molding process, the plastic parts that are scrapped during the time until the mold temperature reaches equilibrium and the loss of time cause start-up losses. Therefore, minimizing preparation time will reduce production costs. With this respect, in this experiment, conformal and straight cooling channels were also compared in terms of start-up losses. Mold conditioner was used for the production trials, and it was expected to reach the working temperature of the mold without production. The time to reach thermal equilibrium for the mold was determined as 75 minutes in the use of the straight channels and 48 minutes in the use of the conformal channels. In experimental and numerical studies conducted in the literature, cycle times were seen to decrease by $15-45 \%$. It is seen that the results obtained in the experiments performed with the method presented in this study are also compatible with the literature.

Table 5. Effects of straight and conformal cooling channels on durations

\begin{tabular}{|c|c|c|c|}
\hline Cooling Channel Type & Cooling Time, $\mathbf{s}$ & Cycle Time, $\mathbf{s}$ & Preparation Time, min \\
\hline Straight & 32 & 44 & 75 \\
\hline Conformal & 25 & 37 & 48 \\
\hline
\end{tabular}

The amount of warpage depth on the planar surfaces of the plastic parts produced in the trial producing were measured with the dial indicator, and their average values were determined. The warpage on the plastic parts produced with the conformal and straight channels is shown in the graphics in Figure 11.
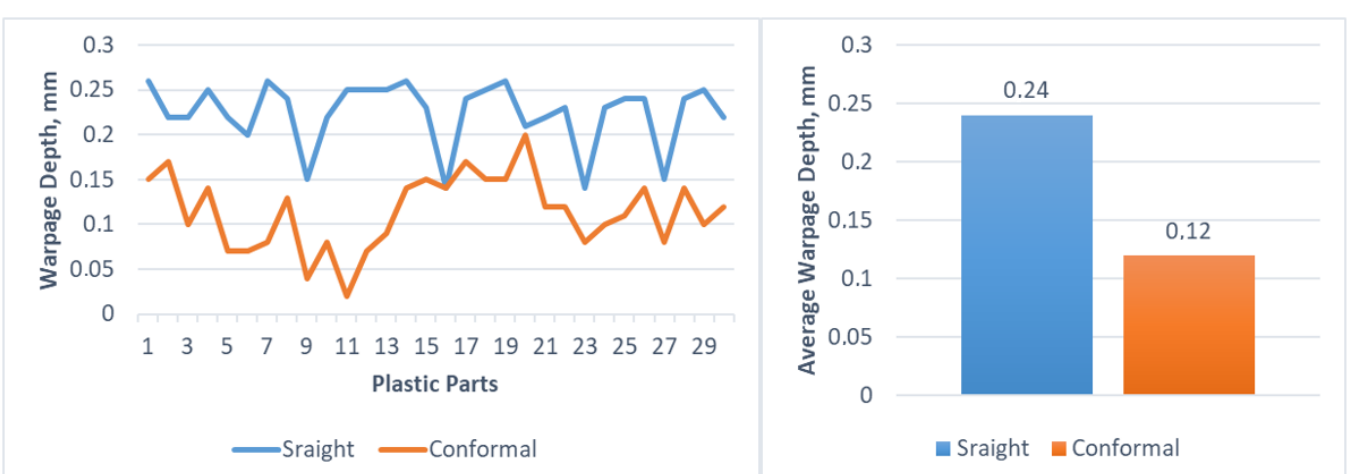

Figure 11. Comparison of the amount of warpage on the plastic parts produced using the conformal and straight channels

The average warpage depth on the plastic parts produced by using the conformal cooling channels was determined as $0.12 \mathrm{~mm}$, and the average warpage depth on the plastic parts produced by using the straight channel was $0.24 \mathrm{~mm}$. With the use of conformal cooling channel, the amount of warpage decreased by $50 \%$, and the quality of the plastic part produced increased. In similar studies in the literature, results consistent with the $25-50 \%$ reduction in the amount of warpage were obtained. This result shows that the conformal cooling channels provide a more uniform temperature distribution. 
Weights of the plastic parts produced by trial producing were measured and compared. The average weights of the plastic parts are shown in the graphic in Figure 12.

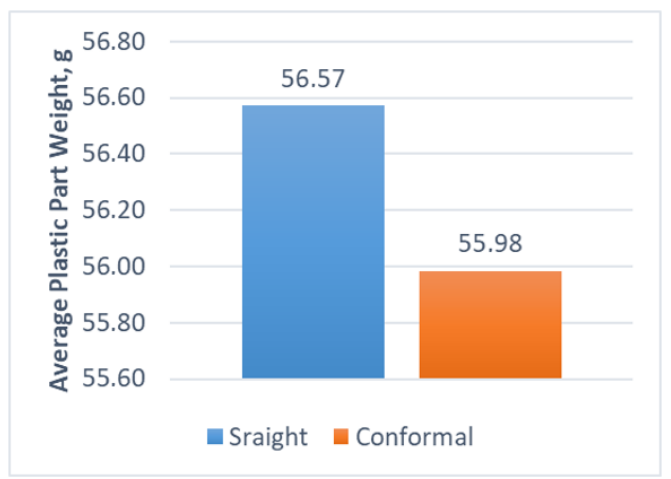

Figure 12. Comparison of the average weights of plastic parts produced using conformal and straight channels

The average weight of the plastic parts produced with the conformal cooling channel was determined as $55.98 \mathrm{~g}$, and the average weight of plastic parts produced with the straight cooling channel was observed as $56.57 \mathrm{~g}$. The parts produced with the conformal channel were approximately $1 \%$ lighter. Considering that the plastic injection molding process is a large volume production method, so the use of conformal cooling channels will save plastic material.

\section{CONCLUSION}

In this study, the effect of conformal cooling channels on the efficiency of the cooling system in plastic injection molds was investigated experimentally. A case study was performed for the plastic part with complex geometry. The cooling channel which would follow the inclined surfaces of the plastic part in conformably was designed with a systematic method. The plastic injection mold with the conformal cooling channel was produced by joining the laminated parts via the vacuum brazing method. The mold was firstly produced in pieces from the grinded steel plates and then joined with the vacuum brazing method.

The plastic parts were produced with plastic injection molds with the straight and conformal cooling channels, and the cooling times were examined. With the use of the shape-adaptive cooling channel, the cooling time decreased from $32 \mathrm{~s}$ to $25 \mathrm{~s}$, and a shortening of about $22 \%$ was achieved. The total cycle time decreased from $44 \mathrm{~s}$ to $37 \mathrm{~s}$. The time to reach the mold thermal equilibrium decreased from 75 min to 48 $\min$.

In the experiments, the amount of warpage on the plastic parts produced was measured and compared. The amount of warpage was reduced by $50 \%$ by using a conformal cooling channel.

With the production method presented, shape-adaptive channels were produced at a lower cost without the need for expensive methods such as metal laser sintering. Both the production speed and plastic part quality were increased. Taking these results into account, an industrially applicable method was presented for many plastic parts with complex geometry.

\section{ACKNOWLEDGEMENTS}

This research was financially supported by Gazi University Projects of Scientific Investigation (BAP) and Project Number: 07/2018-08

\section{CONFLICTS OF INTEREST}

No conflict of interest was declared by the authors. 


\section{REFERENCES}

[1] Dimla, D. E., M. Camilotto, F. Miani., "Design and optimisation of conformal cooling channels in injection moulding tools", Journal of Materials Processing Technology, 164: 1294-1300, (2005).

[2] Yadegari, M., Masoumi, H., Gheisari, M., "Optimization of cooling channels in plastic injection molding", International Journal of Applied Engineering Research, 11(8): 5777-5780, (2016).

[3] Qiao, H., "A systematic computer-aided approach to cooling system optimal design in plastic injection molding", International Journal of Mechanical Sciences, 48(4): 430-439, (2006).

[4] Wang, G. L., Zhao, G. Q., Wang, X. X., "Heating/cooling channels design for an automotive interior part and its evaluation in rapid heat cycle molding", Materials \& Design, 59: 310-322, (2014).

[5] Li, C. G., Li, C. L., Liu, Y., Huang, Y., "A new C-space method to automate the layout design of injection mould cooling system”, Computer-Aided Design, 44(9): 811-823, (2012).

[6] Kovács, J. G., Sikló, B., "Investigation of cooling effect at corners in injection molding", International Communications in Heat and Mass Transfer, 38(10): 1330-1334, (2011).

[7] Altaf, K., Raghavan, V. R., Rani, A. M. A., "Comparative thermal analysis of circular and profiled cooling channels for injection mold tools", Journal of Applied Sciences, 11(11): 2068-2071, (2011).

[8] Hassan, H., Regnier, N., Lebot, C., Pujos, C., Defaye, G., "Effect of cooling system on the polymer temperature and solidification during injection molding", Applied Thermal Engineering, 29(8-9): 17861791, (2009).

[9] Zhou, H., Li, D., "Mold cooling simulation of the pressing process in TV panel production", Simulation Modelling Practice and Theory, 13(3): 273-285, (2005).

[10] Wang, Y., Yu, K. M., \& Wang, C. C., "Spiral and Conformal Cooling in Plastic Injection Molding" Computer-Aided Design 63: 1-11, (2015).

[11] Göktaş, M., Güldaş, A., Bayraktar, Ö., "Cooling of plastic injection moulds using design adaptive cooling canals", International Conference on Engineering and Natural Science (ICENS 2016), Sarajevo, 1987-1993, (2016).

[12] Güldaş, A., Göktaş, M., "Comparison of straight, spiral conformal and zig-zag conformal cooling channels in plastic injection molds", International Symposium on Innovative Approaches in Scientific Studies (ISAS 2019), Ankara, 4(1): 395-399, (2019).

[13] Saifullah, A. B. M., Masood, S. H., Sbarski, I., "New cooling channel design for injection moulding", Proceedings of the World Congress on Engineering, 1:1-4, (2009).

[14] Khan, M., Afaq, S. K., Khan, N. U., Ahmad, S., "Cycle time reduction in injection molding process by selection of robust cooling channel design", ISRN Mechanical Engineering, 2014:1-8, (2014).

[15] Kitayama, S., Tamada, K., Takano, M., Aiba, S., "Numerical and experimental investigation on process parameters optimization in plastic injection molding for weldlines reduction and clamping force minimization", The International Journal of Advanced Manufacturing Technology, 97(5-8): 2087-2098, (2018). 
[16] Lu, C. T., Chen, C. H., Tseng, S. C., "Application of conformal cooling to reduce cooling time and warpage of a U-shaped plate", AIP Conference Proceedings, 2065(1): 030007, (2019).

[17] Shinde, M. S., Ashtankar, K. M., "Additive manufacturing-assisted conformal cooling channels in mold manufacturing processes”, Adv. Mech. Eng., 9(5): 1687814017699764, (2017).

[18] Åsberg, M., Fredriksson, G., Hatami, S., Fredriksson, W., Krakhmalev, P., "Influence of post treatment on microstructure, porosity and mechanical properties of additive manufactured H13 tool steel", Materials Science and Engineering: A, 742: 584-589, (2019).

[19] Jahan, S. A., Wu, T., Zhang, Y., Zhang, J., Tovar, A., Elmounayri, H., "Thermo-mechanical design optimization of conformal cooling channels using design of experiments approach", Procedia Manufacturing, 10: 898-911, (2017).

[20] Rahim, S. Z. A., Sharif, S., Zain, A. M., Nasir, S. M., Mohd Saad, R., "Improving the quality and productivity of molded parts with a new design of conformal cooling channels for the injection molding process", Advances in Polymer Technology, 35(1): 21524, (2016).

[21] Dang, X. P., Park, H. S., "Design of U-shape milled groove conformal cooling channels for plastic injection mold", International Journal of Precision Engineering and Manufacturing, 12(1): 73-84, (2011).

[22] Ferreira, J. C., Mateus, A., "Studies of rapid soft tooling with conformal cooling channels for plastic injection moulding", Journal of Materials Processing Technology, 142(2): 508-516, (2003).

[23] Sun, Y. F., Lee, K. S., Nee, A. Y. C., "Design and FEM analysis of the milled groove insert method for cooling of plastic injection moulds", The International Journal of Advanced Manufacturing Technology, 24(9-10): 715-726, (2004).

[24] Eiamsa-Ard, K., Wannissorn, K., "Conformal bubbler cooling for molds by metal deposition process", Computer-Aided Design, 69: 126-133, (2015).

[25] Göktaş, M., Güldaş, A., "Experimental Comparison of The Effects of Conformal and Straight Cooling Channels", 2nd International Turkish World Engineering and Science Congress, November 7-10, Türkiye, 572-578, (2019).

[26] Bryden, B. G., Pashby, I. R., "Hot platen brazing to produce laminated steel tooling", Journal of Materials Processing Technology, 110(2): 206-210, (2001).

[27] Esmati, K., Omidvar, H., Jelokhani, J., Naderi, M., "Study on the microstructure and mechanical properties of diffusion brazing joint of C17200 Copper Beryllium alloy", Materials \& Design, 53: 766773, (2014).

[28] Bryden, B. G., Pashby, I. R., Wimpenny, D. I., Adams, C., "Laminated steel tooling in the aerospace industry", Materials \& Design, 21(4): 403-408, (2000).

[29] Yoo, S., Walczyk, D. F., "A preliminary study of sealing and heat transfer performance of conformal channels and cooling fins in laminated tooling", Journal of Manufacturing Science and Engineering, 129(2): 388-399, (2007).

[30] Jahan, S. A., El-Mounayri, H., "Optimal conformal cooling channels in 3D printed dies for plastic injection molding", Procedia Manufacturing, 5: 888-900, (2016). 